\title{
Percutaneous trigger finger release
}

\author{
Pandey BK, Sharma S, Manandhar RR, Pradhan RL, Lakhey S, Rijal KP \\ ${ }^{1}$,Department of Orthopaedic Surgery, Kathmandu Medical College Teaching Hospital, Kathmandu, Nepal
}

\begin{abstract}
BACKGROUND: Trigger finger is caused by formation of nodule or thickening of A1 pulley by its fibrocartilage metaplasia resulting in entrapment of the flexor tendon. Conservative treatment of this condition consists of NSAIDs, splint immobilization and steroid injection into the tendon sheath. Failure of the conservative treatment is the indication of an open release. Percutaneous release of trigger finger is advised by several authors. The purpose of this prospective study is to evaluate the results of percutaneous release of trigger finger with 18 gauge needle.
\end{abstract}

METHODS: Fifty one patients with 58 trigger digits were treated by percutaneous release using 18 gauge needle under local anaesthesia. Patients were followed up for an average of 12 months.

RESULTS: Overall, 97\% achieved an excellent or good result. Two digits experienced recurrent symptoms and required an open release. There was no clinical evidence of digital nerve injury or tendon bowstringing.

CONCLUSIONS: We recommend this technique as a safe and effective outpatient procedure for releasing trigger finger.

KEY WORDS: trigger finger, open release, percutaneous release.

\section{INTRODUCTION}

Trigger finger, or stenosing tenosynovitis is characterized by symptomatic locking of clicking flexion and extension of a finger or the thumb $b^{1,2}$. It was first described by Notta in $1850^{1,2}$. There is mismatch between the size of the tendon sheath and the tendon which passes through $\mathrm{it}^{3,4,5}$. It is caused by nodule formation or thickening of A1 pulley by its fibrocartilage metaplasia resulting in entrapment of the flexortendon, thus forming a triggering mechanism ${ }^{6,7}$.

Mostly trigger fingers are idiopathic. It is reported most commonly in middle-age woman and has also been associated with number of conditions, including direct tendon trauma, diabetes mellitus, carpal tunnel syndrome, de Quervain's tenosynovitis, rheumatoid arthritis, hypothyroidism, mucopolysachharidosis, amyloidosis, gout, hypertension, various tumors and neoplasms ${ }^{8,9,10}$.

Several types of conservative treatment have been recommended, including splint immobilization, nonsteroid anti-inflammatory medication, steroid injection with good results in single digit involvement and in early cases ${ }^{4,11,12}$. Surgical release of A1 pulley is indicated when conservative treatment fails ${ }^{13}$.
Complications such as infection, stiffness, scar tenderness, bowstringing and digital nerve injury especially radial digital nerve injury can occur ${ }^{1,14,15}$.

In 1958 Lorthioir first described a technique of percutaneous release of trigger digit using a fine tenotome ${ }^{16}$. Percutaneous release using needle was introduced by Eastwood et. al. ${ }^{17}$ in 1992 with a high success rate. The radial nerve of the thumb was found very close $(2-3 \mathrm{~mm})$ to the A1 pulley ${ }^{18,19,20}$. This has prompted some authors to recommend that thumb should not be treated by percutaneous release ${ }^{17,19,20}$. However others have safely used percutaneous release of trigger thumb $b^{1,3,5,7,9,13,14,21,22,23,24,25}$.

In this study we aimed to evaluate the results of percutaneous release of trigger fingers using $18 \mathrm{G}$ hypodermic needle.

\section{MATERIALS AND METHODS}

This is a prospective study performed at Kathmandu Medical College Teaching Hospital from February 2007 to December 2008 on 58 digits in 51 patients. There were 37 female and 14 males with mean age of $52(26-65)$ years. 39 thumbs, 11 ring fingers, 6 
NEPAL ORTHOPAEDIC ASSOCIATION JOURNAL (NOAJ)

VOLUME1, NUMBER ONE, JANUARY 2010

middle fingers, 1 index and 1 little finger were involved. Duration of triggering was with average of 6 months (range 2 months -10 years). Associated medical illness were diabetes mellitus in 12 patients, history of carpal tunnel syndrome in 5 patients and rheumatoid arthritis in 3 patients.

Triggering of the digits was graded according to the severity of symptoms as devised by previous study ${ }^{25}$.

\section{LEGEND-1}

\begin{tabular}{ccc}
\hline Grade & Symptoms & No of cases \\
\hline \hline I & $\begin{array}{c}\text { No triggering, but } \\
\text { uneven finger movement } \\
\text { II }\end{array}$ & $\begin{array}{c}\text { Actively correctable } \\
\text { triggering } \\
\text { Triggering usually }\end{array}$ \\
III & $\begin{array}{c}\text { correctable by the other } \\
\text { hand }\end{array}$ & $40(69 \%)$ \\
IV & Locked digit & $14(14 \%)$ \\
\hline
\end{tabular}

Patients with grade 2, 3 and 4 who had not responded to conservative treatment or recurrence of trigger digit after injection of steroid at least for two episodes were included in the study.

As explained by Bain et.al. ${ }^{19}$ and Cihantimur et.al. ${ }^{5}$, the procedure was performed under local anaesthesia. Precise location of the A1 pulley is important. The point of triggering was located easily by palpation. The surface landmarks of the proximal edge of A1 pulley were marked. These are the metacarpophalangeal crease of the thumb, the proximal palmar crease of the index finger, halfway between the proximal and distal palmar creases of middle and the distal palmar creases of the ring and little fingers ${ }^{9,19,25}$.

The finger was held firmly and hyper-extended at the metacarpophalangeal joint. Hyperextension is essential, as it causes the flexor tendon sheath to lie directly under skin and allows the digital neurovascular bundles to displace to either side ${ }^{5,7,19}$. A $18 \mathrm{G}$ hypodermic needle was inserted into the flexor tendon sheath or nodule proximally, with the bevel of the needle oriented along the line of the finger. Position of the needle in the tendon sheath was confirmed by actively flexing the digit and observing the motion of the needle. The needle was then withdrawn slightly until it ceases to move with flexion of the finger tip. The A1 pulley was cut by moving
PERCUTANEOUS TRIGGER FINGER RELEASE, Pandey BK, Sharma S, Manandhar RR, Pradhan RL, Lakhey S, Rijal KP

bevel of the needle longitudinally from proximal to distal. A grating sensation could be felt by the operator as the needle tip cut through the transverse fibres of the A1 pulley. Loss of the grating sensation indicated completion of the release, the patient was asked to flex and extend the finger to verify the success of the procedure. Adequate release of the pulley was shown by disappearance of the triggering on active movement of the digit. If a patient demonstrated continued triggering the needle was reinserted more distally and additional release was performed. A small dressing was used for a day and the patient was allowed to return to normal activities immediately post-operatively. Analgesic was prescribed for two days and then if needed.

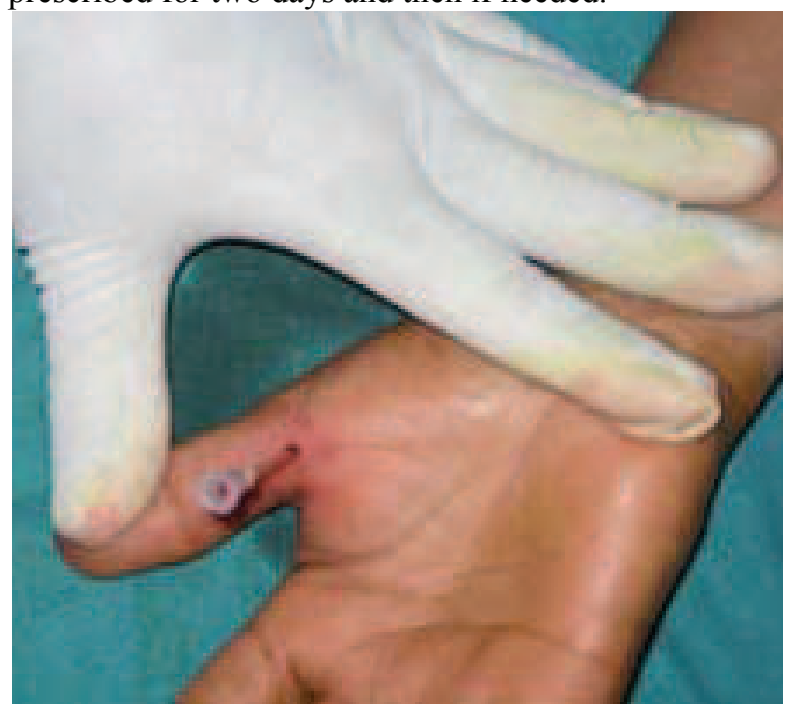

Fig. 1 The initial location for introduction of the 18 gauge needle is centre of the metacarpophalangeal crease of the thumb

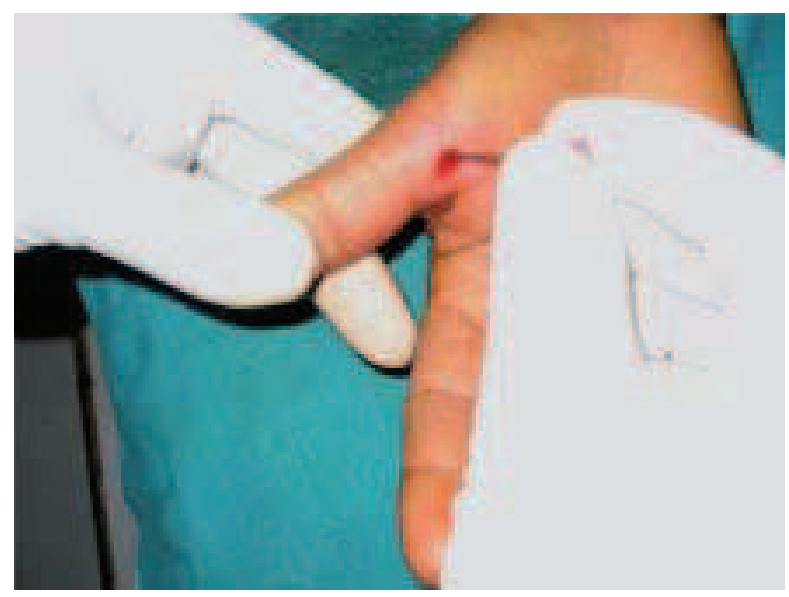

Fig. 2 The A1 pulley is cut by moving bevel of the needle longitudinally from proximal to distal 
All the patients were followed up for an average of 12 months (6-18 months) after operation in outpatient or by telephone. Outcome grading was done at 3 month according to Quinell's criteria (Table 2) ${ }^{24}$.

\section{LEGEND-2}

\begin{tabular}{ll}
\hline Grade & Symptoms \\
\hline I & Normal movement, no pain \\
II & Normal movement, occasional pain \\
III & Uneven movement \\
IV & Intermediate locking, actively correctable \\
V & Locking, only passively correctable \\
\hline
\end{tabular}

Grade I: $\quad$ Excellent

Grade II: $\quad$ Good

Grade III - V: Poor

\section{RESULTS}

A successful percutaneous release was achieved in 56 of the 58 trigger digits (97\%). According to Quinnell grading system (Table 2), excellent result was found in 42 digits (73\%), good in 14 (24\%). In two digits (3\%) percutaneous method failed to relieve the triggering completely. These included middle and ring fingers. 14 digits with good result had normal finger movement, but had occasional pain. In all these cases symptoms resolved within 6 months with simple analgesic when required. None of the patients who had an excellent or good result experienced any long term pain or discomfort. Two digits with persistent triggering underwent open release with complete resolution of symptoms. Both of these digits were found to have had an incomplete release of the distal portion of the A1 pulley.

None of the patients had complications such as infection, digital nerve injury, vascular injury and tendon bowstringing.
Table 3

\begin{tabular}{ccccc}
\hline Digits & $\begin{array}{c}\text { No. of } \\
\text { cases }\end{array}$ & Excellent & $\begin{array}{c}\text { Results } \\
\text { Good }\end{array}$ & Poor \\
\hline Thumb & 39 & $30(77 \%)$ & $9(23 \%)$ & - \\
Index & 1 & - & $\begin{array}{c}1 \\
(100 \%)\end{array}$ & - \\
Middle & 6 & $4(66 \%)$ & $1(17 \%)$ & $1(17 \%)$ \\
Ring & 11 & $8(73 \%)$ & $2(18 \%)$ & $1(9 \%)$ \\
Little & 1 & - & $\begin{array}{c}1 \\
(100 \%)\end{array}$ & - \\
Overall & 58 & $42(73 \%)$ & $\begin{array}{c}14 \% \\
(24 \% 0\end{array}$ & $2(3 \%)$ \\
\hline
\end{tabular}

\section{DISCUSSION}

Stenosing tenosynovitis, trigger digit, is a condition for which many treatment modalities have been recommended. NSAIDs, splinting and injection of steroid have been advocated by number of authors. These conservative modalities have been successful in $57 \%$ to $97 \%$ of cases $^{8,10,12,26,27,28}$. Marks and Gunther ${ }^{28}$ in their series of 108 trigger digits found $92 \%$ of trigger thumb were cured with single dose of steroid injection and $97 \%$ cured after repeated injections. Corticosteroid injection therapy appeared to be more successful in a semi-acute setting and less useful in more advanced cases. The shuccess rate when triggering had been first noticed less than a month before diagnosis was higher than in patients who had been symptomatic for 6 months or more ( $88 \%$ vs $65 \%)^{29}$. Other studies demonstrated even lower success rate (55\% Newport et.al. ${ }^{26}, 45 \%$ Rhodes et. al. ${ }^{11}$ ) when symptoms had been present for more than 6 months. Failure of these methods has resulted in the need for surgical release of the A1 pulley.

Satisfactory results of $60 \%$ to $100 \%$ have been reported after open release with $7 \%$ to $28 \%$ of complications, such as digital nerve injury, infection, stiffness, weakness, scar tenderness and bowstringing of the flexor tendons ${ }^{2,4,19,29,30}$.

Percutaneous release of the trigger digit was first described by Lorthior in 1958 using a fine tenotome ${ }^{16}$. He reported good results in all 52 patients with no neurovascular complications. Tanala et. al. ${ }^{34}$ reported $64.3 \%$ excellent, $9.5 \%$ good, $8.1 \%$ fair and $18.1 \%$ poor results following subcutaneous release of 210 trigger 
NEPAL ORTHOPAEDIC ASSOCIATION JOURNAL (NOAJ) VOLUME1, NUMBER ONE, JANUARY 2010
PERCUTANEOUS TRIGGER FINGER RELEASE, Pandey BK, Sharma S, Manandhar RR, Pradhan RL, Lakhey S, Rijal KP digits with a fine scalpel (Bain 1995). Lyu $^{31}$ in 1992 performed a closed tenotomy with a curved knife blade in 16 trigger thumb and had high success rate without damaging the digital nerve. Ha et. al. ${ }^{25}$ in 2001 used a special blade with a hook end and reported 92\% (72 of 79) satisfactory result. Park et. al. ${ }^{32}$ in 2004 used similar blade with a hook (HAKI knife) for percutaneous release of locked trigger digit with $91 \%$ (107 of 118) success result. Jongjirasiri ${ }^{23}$ (2007) used $15^{\circ}$ full handle knife for percutaneous release of trigger digits with success rate of $92.9 \%$ (314 of 334).

Percutaneous division of the A1 pulley using a 21 gauge needle was first reported by Eastwood et. $\mathrm{al}^{17}$ in 1992 with success rate of $94 \%$ in 35 trigger digits. The average distance from A1 pulley to the digital nerves in the thumb is $2.9 \mathrm{~mm}$ at the metacarpophalangeal crease $^{19,20}$. This proximity of the digital nerve to the A1 of the thumb has prompted some authors to recommend that this should not be treated by percutaneous release ${ }^{17,19,20}$. However other authors have safely used

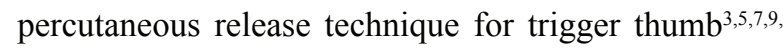
13,14,21,22,24,25,32,33. Maneerit et. al. ${ }^{14}$ recommended that in order to prevent digital nerve damage the needle should be held above the tendon in the midline of the thumb and radial approach should be avoided. Secondly, the needle should be inserted a few millimetres distal to the metacarpophalangeal flexion crease. Thirdly, the thumb should be held in full extension during the procedure as this will move the tendon and A1 pulley anterior to the neurovascular bundle. Fourthly, the forearm should be placed in hypersupination to place the palmar surface of thumb in a horizontal plane for good orientation. Several authors 7, 13, 14, 17,21, 24,33 performed percutaneous release of trigger digits by needle with success rate ranging from $91 \%$ to $96 \%$. Cihantimur et. al. ${ }^{5}$ and Gilberts et. al. ${ }^{22}$ claimed success rate of $100 \%$ with this method of treating trigger digits.

None of the patients in the above studies had digital nerve injury after percutaneous release of trigger digits, including thumb.

In our study, successful percutaneous release was achieved in 97\% (56 of 58) trigger digits. In 3\% (2 of 58 ); middle and one ring finger; this method failed to relieve the triggering. Both of the digits were found to have an incomplete release of the distal portion of the
A1 pulley. In our study also none of the patients had digital nerve injury or tendon bowstringing.

\section{CONCLUSIONS}

We conclude that percutaneous release of trigger fingers can safely and effectively be performed with 18 gauge needle, even of the thumb. This technique can be performed as an outpatient procedure.

\section{REFERENCES:}

1. Ryzewicz M,Wolf JM. Trigger digits: Principles, management, and complications. J Hand Surg 2006; 31A:135-146.

2. Makkouk AH, Oetgen ME, Swigart CR, Dodds SD. Trigger finger: etiology, evaluation, and treatment. Curr Rev Musculoskelet Med 2008; 1:92-96.

3. Joy AK, Brogen AK, Wangjam K, Singh I, Bimol N, Nilachandra L. Percutaneous release of trigger fingers: Is it reserved for few surgeons? IJPMR 13, April 2002; $1-4$.

4. Kolind-Sorensen V. Treatment of trigger fingers. Acta Orthop Scandinav 1970; 41:428-432.

5. Cihantimur B, Akin S, Ozcan M. Percutaneous treatment of trigger finger. 34 fingers followed 0.5-2 years. Acta Orthop Scand 1998;69 (2):167-168.

6. Sampson SP, Badalamente MA. Pathology of the human A1 pulley in trigger finger. J Hand Surg 1991;16(4) A:714-721.

7. Cebesoy O, Karakurum G, Kose KC, Baltaci ET, Isik M. Percutaneous release of the trigger thumb: Is it safe, cheap and effective? International Orthopaedics (SICOT) 2007; 31:345-249.

8. Nimigan AS, Ross DC, Gan BS. Steroid injections in the management of trigger fingers. Am J Phys Med Rehabil 2006; 85:36-43.

9. Saldana MJ. Trigger digits: diagnosis and treatment. J Am Acad Orthop Surg 2001; 9:246-252.

10. Murphy D, Failla JM, Koniuch MP. Steroid versus placebo injection for trigger finger. J Hand Surg 1995; 20A:628-631.

11. Rhoades CE, Gelberman MD, Manjarris JF. Stenosing tenosynovitis of the fingers and thumb. Clin Orthop 1984; 190:236-238.

12. Patel MR, Bassini L. Trigger fingers and thumb: When to splint, inject, or operate. J Hand Surg 1992;17(1):110113. 
NEPAL ORTHOPAEDIC ASSOCIATION JOURNAL (NOAJ) VOLUME1, NUMBER ONE, JANUARY 2010
PERCUTANEOUS TRIGGER FINGER RELEASE, Pandey BK,

Sharma S, Manandhar RR, Pradhan RL, Lakhey S, Rijal KP
13. Blumberg N, Arbel R, Dekel S. Percutaneous release of trigger digits. J Hand Surg (British \& European volume) 2001;26(3):256-257.

14. Maneerit J, Sriworakun C, Budhraja N, Nagavajara P. Trigger thumb: results of prospective randomised study of percutaneous release with steroid injection versus steroid injection alone. J Hand Surg (British \& European volume) 2003;28(6):586-589.

15. Carrozella J, Stern PJ, Von Kuster LC. Transection of radial digital nerve of the thumb during trigger release. J Hand Surg (Am) 1989; 14(2):198-200.

16. Lorthioir J. Surgical treatment of trigger-finger by a subcutaneous method. J Bone Joint Surg 1958; 40A:793795.

17. Eastwood DM, Gupta KJ, Johnson DP. Percutaneous release of trigger finger: an office procedure. J Hand Surg 1992; 17A:114-117.

18. Slesarenko YA, Mallo G, Hurst LC, Sampson SP, Serra-Hsu F. Techniques in hand and upper extremity surgery 2006; 10(1):54-56.

19. Bain GI, Turnbull J, Charles MN, Roth JH, Richards RS. Percutaneous A1 pulley release: A cadaveric study. J Hand Surg 1995; 20A:781-784.

20. Pope DF, Wolfe SW. Safety and efficacy of percutaneous trigger finger release. J Hand Surg 1995; 20A280-283.

21. Patel MR, Moradia VJ. Percutaneous release of trigger digit with and without cortisone injection. J Hand Surg 1997; 22A:150-155.

22. Gilberts ECAM, Beekman WH, Stevens HJPD, Wereldsma JCJ.Prospectiverandomized trial of open versus percutaneous surgery for trigger digits. J Hand Surg 2001;26A: 497-500.

23. Jongjirasiri Y. The results of percutaneous release of trigger digits by using handle knife $15^{\circ}$ : An anatomical hand sirface landmark and clinical study. J Med Assoc Thai 2007;90 (7):1348-55.
24. Ragoowansi R, Acornley A, Khoo CT. Percutaneous trigger finger release: the 'lift-cut' technique. British Journal of Plastic Surgery 2005; 58:817-821.

25. Ha KI, Park MJ, Ha CW. Percutaneous release of trigger digits. A technique and results using specially designed knife. J Bone Joint Surg (Br) 2001; 83B:75-77.

26. Newport ML, Lane LB, Stuchin SA. Treatment of trigger finger by steroid injection. J Hand Surg 1990;15:748-750.

27. Lambert MA, Morton RJ, Sloan JP. Controlled study of the use of local steroid injection in the treatment of trigger finger and thumb. J Hand Surg (British and European volume) 1992;17(1):69-70.

28. Marks MR, Gunther SF. Efficacy of cortisone injection in treatment of trigger fingers and thumb. J Hand Surg 1989;14A:722-729.

29. Turowski GA, Zdankiewicz PD, Thomson JG. The results of surgical treatment of trigger finger. J Hand Surg 1997; 22A:145-149.

30. Vaes F, Smet LD, Ransbeeck HV, Fabry G. Surgical treatment of trigger fingers. Acta Orthopaedica Belgica 1998; 64(4):363-365.

31. Lyu SR. Closed division of the flexor tendon sheath for trigger finger. J Bone Joint Surg 1992;74-B:418-420.

32. Park MJ, Oh I, Ha KI. A1 pulley release of locked trigger digit by percutaneous technique. J Hand Surg (British and European volume) 2004; 29B:502-505.

33. Schramm JM, Nguyen M, Wongworawat MD. The safety of percutaneous trigger finger release. Hand 2008; 3:44-46.

34. Tanaka M, Muraji M, Negoro H, Yamashita H, Nakano T, Nakano K. Subcutaneous release od trigger thumb and fingers in 210 fingers. J Hand Surg (British and European volume) 1990; 15(4):463-465.

bimalpandey@hotmail.com 